\title{
Meiotic chromosome movements in plants, a puppet show?
}

\author{
Javier Varas ${ }^{1 *}$ and Célia Baroux ${ }^{2}$ \\ ${ }^{1}$ Departamento de Genética, Facultad de Biología, Universidad Complutense de Madrid, Madrid, Spain \\ ${ }^{2}$ Department of Plant Developmental Genetics, Institute of Plant Biology, Zürich-Basel Plant Science Center, University of Zürich, Zürich, Switzerland \\ *Correspondence: j.varas@pdi.ucm.es
}

\section{Edited by:}

Katja Graumann, Oxford Brookes University, UK

Reviewed by:

Veit Schubert, Leibniz Institute of Plant Genetics and Crop Plant Research, Germany

Emmanuel Vanrobays, Blaise Pascal University, France

Keywords: telomere, SUN, nuclear envelope, bouquet, meiosis

\section{A commentary on}

A dynamic meiotic SUN belt includes the zygotene-stage telomere bouquet and is disrupted in chromosome segregation mutants of maize (Zea mays L.)

by Murphy, S. P., Gumber, H. K., Mao, Y., and Bass, H. W. (2014). Front. Plant Sci. 5:314. doi: 10.3389/fpls.2014.00314

Meiosis is a special type of cell division by which sexually reproducing organisms maintain their chromosome number across generations. This process produces haploid gametes by two successive rounds of cell division preceded by a unique DNA replication event. During the first meiotic prophase, the homologous chromosomes form stable bivalents, a process which implies their recognition, with a subsequent step of intimate alignment (pairing), synapsis (physical association of paired chromosomes by the synaptonemal complex, SC), and recombination (exchange of chromosomal regions).

Usually, homologous chromosomes are physically separated at initiation of prophase I. In many organisms, telomeres initiate a non-random movement at the entrance of meiosis that brings homologs together tethering at the inner surface of the nuclear envelope (NE).

Sad1/UNC-84 (SUN)-domain proteins are inner NE proteins involved in complexes that link cytoskeletal elements

\section{LINC complexes during Meiosis}

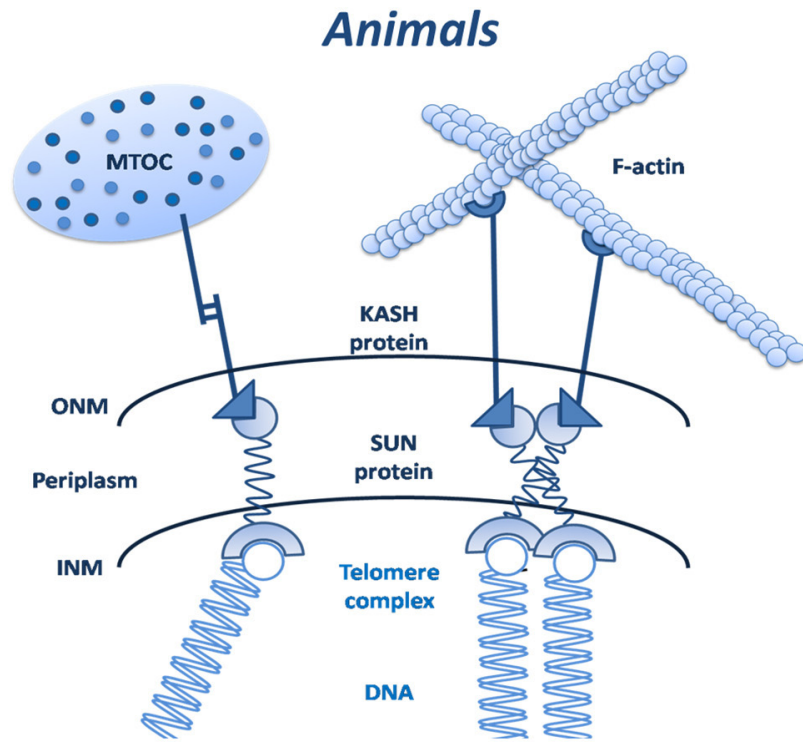

FIGURE 1 | Working model for the LINC complexes during meiosis. These, are able to act as molecular bridges in animals (left panel). By contrast, this function remains unknown in plants (right panel). LINC complexes allows the cytoskeleton to regulate

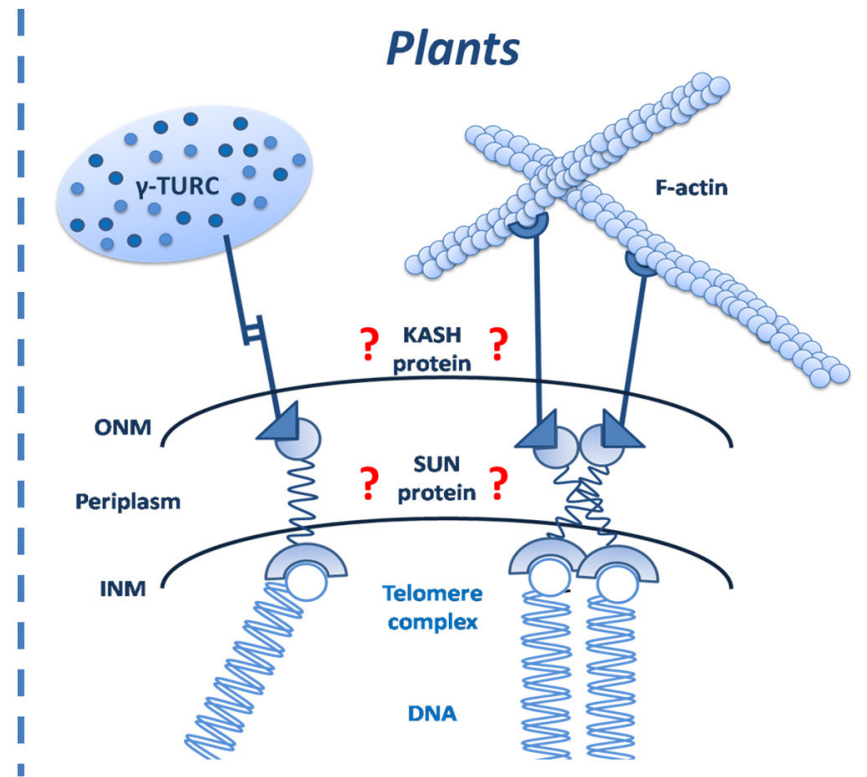

the telomere position within the nucleus. (MTOC, microtubule-organizing center; LINC, Linker of Nucleoskeleton and Cytoskeleton; ONM, outer nuclear membrane; INM, inner nuclear membrane; $\gamma$-TURC, gamma-tubulin ring complex). 
with the nucleoskeleton. In this sense, the SUN proteins connect the telomeres in order to generate the chromosome arrangements, acting as the strings for puppet movements. This telomere attachment to the NE and telomere clustering at the transition between leptotene and zygotene (defining a stage called the "bouquet") are well-known meiotic phenomena (Zickler and Kleckner, 1998). Numerous lines of evidence obtained in several non-plant model species suggest that they are driven by the meiotic cytoskeleton (Figure 1). Also, it has been shown that disruption of the telomere/nuclear envelope attachment during meiosis induces alterations in pairing and synapsis (Kracklauer et al., 2013).

The existence of several SUN domain proteins in plants has been described. Graumann et al. (2010) and Murphy et al. (2010). However, the specific role of these proteins during plant meiosis remained largely enigmatic (Figure 1; Roberts et al., 2013). In this issue of Frontiers in Plant Sci. Murphy et al. (2014) provide new evidences that the SUN proteins could be factors involved in facilitating the chromosome movements during the first meiotic prophase. Observations from the Hank Bass laboratory are focused on cytological analyses of maize SUN domain proteins during meiotic prophase. The authors have developed a new antibody against the two SUN proteins from maize and they demonstrate the existence of a characteristic "SUN belt" around the NE. Furthermore, their data suggest interactions between these SUN proteins and the telomeres when the bouquet formation occurs. The work of Murphy et al. (2014) using three classic maize meiotic mutants, provides further insights into the role of SUN proteins in controlling the chromosome movements in plant meiosis. This study is a first step toward a better understanding of chromosome dynamics during the meiotic program.

\section{ACKNOWLEDGMENTS}

The authors thank Mónica Pradillo (Universidad Complutense) for her critical reading of the manuscript. Javier Varas is supported at Juan Santos Group by the European Union FP7 grant (Meiosys-KBBE-2009-222883).

\section{REFERENCES}

Graumann, K., Runions, J., and Evans, D. E. (2010). Characterization of SUN-domain proteins at the higher plant nuclear envelope. Plant J. 61, 134-144. doi: 10.1111/j.1365-313X.2009.04038.x

Kracklauer, M. P., Link, J., and Alsheimer, M. (2013). LINCing the nuclear envelope to gametogenesis. Curr. Top. Dev. Biol. 102, 127-157. doi: 10.1016/B978-0-12-416024-8.00005-2

Murphy, S. P., Gumber, H. K., Mao, Y., and Bass, H. W. (2014). A dynamic meiotic SUN belt includes the zygotene-stage telomere bouquet and is disrupted in chromosome segregation mutants of maize (Zea mays L.). Front. Plant Sci. 5:314. doi: 10.3389/fpls.2014.00314
Murphy, S. P., Simmons, C. R., and Bass, H. W. (2010). Structure and expression of the maize (Zea mays L.) SUN-domain protein gene family: evidence for the existence of two divergent classes of SUN proteins in plants. BMC Plant Biol. 10:269. doi: 10.1186/1471-2229-10-269

Roberts, N. Y., Osman, K., Chris, F., Franklin, H., Pradillo, M., Varas, J., et al. (2013). “Telomeres in plant meiosis: their structure, dynamics and function" in Annual Plant Reviews: Plant Nuclear Structure, Genome Architecture and Gene Regulation, Vol. 46, eds D. E. Evans, K. Graumann, and J. A. Bryant (Oxford, UK: John Wiley and Sons Ltd), 191-228. doi: 10.1002/978111847 2507.ch7

Zickler, D., and Kleckner, N. (1998). The leptotenezygotene transition of meiosis. Annu. Rev. Genet. 32, 619-697. doi: 10.1146/annurev.genet. 32.1 .619

Conflict of Interest Statement: The authors declare that the research was conducted in the absence of any commercial or financial relationships that could be construed as a potential conflict of interest.

Received: 22 August 2014; paper pending published: 05 September 2014; accepted: 09 September 2014; published online: 29 September 2014.

Citation: Varas J and Baroux C (2014) Meiotic chromosome movements in plants, a puppet show?. Front. Plant Sci. 5:502. doi: 10.3389/fpls.2014.00502

This article was submitted to Plant Cell Biology, a section of the journal Frontiers in Plant Science.

Copyright (c) 2014 Varas and Baroux. This is an openaccess article distributed under the terms of the Creative Commons Attribution License (CC BY). The use, distribution or reproduction in other forums is permitted, provided the original author(s) or licensor are credited and that the original publication in this journal is cited, in accordance with accepted academic practice. No use, distribution or reproduction is permitted which does not comply with these terms. 